\title{
Correlations between the Status of the Umbilical Cord and Neonatal Health Status
}

\author{
Sun Min Lee ${ }^{1}$, Dong Yeon Kim ${ }^{2}$, Seongmin $\mathrm{Cho}^{1}$, Sun Mi Noh ${ }^{3}$, Hye Ly Park ${ }^{1}$, Gyungjoo Lee ${ }^{4}$ \\ ${ }^{1}$ Registered Nurse, Newborn Nursery, Seoul St. Mary's Hospital, The Catholic University of Korea, Seoul; ${ }^{2}$ Unit Manager, Neonatal Intensive Care Unit, Seoul St. \\ Mary's Hospital, The Catholic University of Korea, Seoul; ${ }^{3}$ Registered Nurse, Newborn Nursery, Eunpyeong St. Mary's Hospital, The Catholic University of Korea, \\ Seoul; ${ }^{4}$ Associate Professor, College of Nursing, The Catholic University of Korea, Seoul, Korea
}

Purpose: This study aimed to identify correlations between the status of the umbilical cord and neonatal health status. Methods: In total, 172 newborns were enrolled who were admitted to the newborn nursery with a gestational age of 35 weeks or older and a body weight of $2 \mathrm{~kg}$ or above. Data were collected on the basic personal information of the newborns, the diameter and soft tissue status of the umbilical cord, and neonatal health status after birth. Analyses were performed using t-test, analysis of variance, $x^{2}$ test, and Fisher exact test. Results: Umbilical cord diameter exhibited a statistically significant difference by sex $(\mathrm{t}=2.71, p=.007)$. A thin umbilical cord diameter was associated with a 1-minute Apgar score less than 8 points $(\mathrm{t}=2.47, p=.015)$ and with being transferred to the intensive care unit $(\mathrm{t}=2.45, p=.015)$. Poor soft tissue status of the umbilical cord was associated with a 1-minute Apgar score of less than 8 points $\left(\chi^{2}=16.68, p<.001\right)$ and with oxygen being supplied $\left(\chi^{2}=4.81, p=.028\right)$. Conclusion: Assessing the umbilical cord diameter and status in newborns is an important tool for evaluating neonatal health status after birth, and this point also underscores the importance of professionals' careful observations in the newborn nursery.

Key words: Umbilical cord; Infant, newborn; Health status

\section{Corresponding author Dong Yeon Kim \\ https://orcid.org/0000-0001-9500-5792}

Neonatal Intensive Care Unit, Seoul St. Mary's Hospital, The Catholic University of Korea, 222 Banpo-daero, Seocho-gu, Seoul 06591, Korea

TEL +82-2-2258-3044 FAX +82-2-2258-2958

E-MAIL vonma98@naver.com

*This study was supported by the research fund of Seoul St. Mary's Hospital, the Catholic University of Korea in 2018.

Received May 21, 2020 Revised Jun 3, 2020 Accepted Jun 15, 2020 (a) This is an Open Access article distributed under the terms of the Creative Commons Attribution NonCommercial License (http://creativecommons.org/licenses/by-nc/4.0/) which permits unrestricted noncommercial use, distribution, and reproduction in any medium, provided the original work is properly cited.

\section{INTRODUCTION}

\section{Need for Study}

The umbilical cord, which consists of two arteries and one vein, connects the fetus with the placenta for blood circulation and has a significant influence on the development of the fetus [1-3]. The umbilical cord contains Wharton's jelly, which is a gelatinous substance composed of mucous polysaccharides that protects the blood vessels. A reduction in the amount of Wharton's jelly may be linked to fetal death due to a single umbilical artery, a condition in which three blood vessels form an abnormally coiled shape in the absence of sufficient Wharton's jelly [4]. The umbilical cord is commonly considered to lose its function after birth, but many studies published in international nursing journals have reported that the umbilical cord can be divided into a healthy umbilicus, an umbilicus at risk, and an unhealthy umbilicus to be observed, and that appropriate care is required according to umbilical cord status, as it directly affects the health of newborns [5]. A reduction in the diameter of the umbilical cord is associated with morbid factors of the placenta. According to the literature, a knot in a newborn's umbilical cord is referred to as a true knot of the umbilical cord. It can be caused by high levels of amniotic fluid in the womb or inadvertent cord entanglement when the fetus 
is active inside the womb [6]. Umbilical cord entanglement and umbilical cord knot increase the risks of an emergency cesarean section, fetal asphyxia, meconium- stained amniotic fluid, a low Apgar score, and neonatal death $[7,8]$.

The prenatal umbilical cord is the lifeline that supplies oxygen and nutrients to the fetus, and entanglement or problems with the umbilical cord mean that oxygen is not supplied, resulting in a strangulating effect, as well as potentially leading to intrauterine growth retardation or premature birth, which may require intensive treatment. The umbilical cord having stained meconium indicates fetal stress, which may increase the risks of neonatal jaundice, neonatal sepsis, newborn respiratory distress syndrome, and meconium aspiration syndrome [9]. Studies have emphasized the importance of observing umbilical cord status through ultrasonography as part of prenatal care and during pregnancy [10], and have pointed out the practicality of using disinfectants or nursing methods for umbilical cord separation [11], but the importance of observing the thickness and status of the umbilical cord is still under-recognized in the clinical setting, to the point that the umbilical cord may not even be measured with a tape measure. The reason for this lack of awareness may be the inaccurate perception that the umbilical cord loses its function when separated from the mother after the neonate is born [3].

In this study, therefore, the diameter and status of the umbilical cord of newborns admitted to the newborn nursery were observed in place of fetal ultrasound to identify correlations with neonatal health status and to determine whether umbilical cord status is predictive of newborns' health status after birth.

Previous studies have focused on the umbilical separation time or disinfection, but this study differs in that it investigates the health status of newborns and concludes that the diameter and condition of the umbilical cord should be observed immediately after birth.

\section{Purpose}

In detail, the purposes of this study are as follows.

- To identify differences in umbilical cord status (diameter and soft tissue status) according to general characteristics

- To identify relationships between neonatal health status and the umbilical cord diameter

- To identify relationships between neonatal health status and the soft tissue status of the umbilical cord

\section{Definitions of Terms}

\section{1) Diameter of the umbilical cord}

The diameter was defined as a straight line passing through the center of the umbilical cord, connecting two points on the circumference. It was measured $2 \mathrm{~cm}$ away from the newborn's abdomen and calculated by the following equation: diameter $=$ circumference $/ \pi$.

\section{2) Soft tissue status of the umbilical cord}

The soft tissue status of the umbilical cord was assessed based on a visual observation of the umbilical cord, including parameters such as its elasticity and transparency. A clean umbilical cord was considered good, while stained meconium or the presence of a cyst, hematoma, knot, or a thin and unclear umbilical cord was considered to indicate poor status.

\section{3) Neonatal health status}

Neonatal health status is the overall health status of a newborn after birth, including the Apgar score, vital signs, oxygen saturation, and respiration status [12]. In this study, the following parameters were analyzed: the Apgar score of newborns after birth; saturation of percutaneous oxygen $\left(\mathrm{SpO}_{2}\right)$ at arrival and 30 minutes, 1 hour, 2 hours, and 4 hours after arrival; the growth curve; whether oxygen was supplied; and whether the newborn was taken to the intensive care unit (ICU).

The uterine growth curve graph showed the newborn's weight, head circumference, and length after birth in terms of percentiles according to the WHO Child Growth Standards [13].

\section{METHODS}

\section{Study Design}

This research is a comparative descriptive study that investigated the correlations of the diameter and the soft tissue status of the umbilical cord with neonatal health status, including the growth curve percentile, oxygen saturation, the Apgar score, whether oxygen was supplied, and transfer to the ICU.

\section{Subjects}

The subjects were selected from newborns at C University Hospital located in Seoul, South Korea, who were healthy and admitted to the newborn nursery within 30 minutes after birth. The enrolled newborns had a gestational age of 35 weeks or older and a body weight of $2 \mathrm{~kg}$ or above. The minimum sample size was 150 when calculated based on an effect size of .30, a significance level of .05 , and a statistical power of .80 using $G^{*}$ Power (version 3.1.9.2.). Considering a withdrawal rate of $15 \%$, the calculated final sample size was 175 . Excluding three consent forms that contained unclear answers, a total of 172 
neonates were included in the analysis. Specifically, all the newborns admitted to the newborn nursery were potential subjects, but those with a cord cyst $2 \mathrm{~cm}$ away from the abdomen were excluded to ensure consistency in the measurements of the umbilical cord diameter.

\section{Study Tool}

\section{1) Disinfected tape measure for umbilical cord diameter}

To measure the umbilical cord, 150-cm tape measures were purchased and cut into $10-\mathrm{cm}$ pieces, which were disinfected and discarded after each use. The circumference was measured and then divided by pi $(\pi)$ to determine the diameter. The umbilical cord circumference was measured $2 \mathrm{~cm}$ away from the newborn's abdomen within 1 hour of birth using the disinfected tape measure and wearing disinfected gloves. Four nurses (co-authors with at least 5 years of experience) collected the measurements, and the umbilical cord diameter of eight newborns was measured three times each in order to reduce the discrepancy between measurers. The reliability between the measurers was .97 .

\section{2) Soft tissue status of the umbilical cord}

A clean umbilical cord was considered to be good, while stained meconium or the presence of a cyst, hematoma, knot, or a thin and unclear umbilical cord was considered to indicate poor status.

\section{3) Neonatal health status}

(1) Growth curve

The uterine growth curve was shown as a graph indicating the newborn's weight, head circumference, and length after birth as less than the 10th percentile, 10 90th percentile, and greater than the 90th percentile. The 10 90th percentile range was considered normal in this study, while $<10$ th percentile or $>90$ th percentile values were considered to be abnormal, indicating that neonates were small for gestational age or large for gestational age, respectively. Head circumference was measured by wrapping the tape snugly around the widest possible circumference, from the most prominent part of the forehead around to the widest part of the back of the head. The length was measured using a soft, flexible measuring tape from the top of the head to the heel, gently stretching out the baby's leg to obtain the most accurate measurement. Body weight at birth was measured in the delivery room.

(2) Saturation of percutaneous oxygen

$\mathrm{SpO}_{2}$ levels were measured using the same equipment (YM500ST, MEDIANA, Korea) at arrival and 30 minutes, 1 hour, 2 hours, and 4 hours after arrival at the newborn nursery. The average of the measurements was calculated. The normal value of $\mathrm{SpO}_{2}$ was $95 \sim 100 \%$, while values less than 95\% showed improper perfusion.

\section{(3) Apgar score}

The Apgar score was measured 1 and 5 minutes after birth. The criteria for being admitted to the newborn nursery were a 1-minute Apgar score of more than 6 points and a 5-minute Apgar score of more than 7 points. A 1-minute Apgar score of less than 8 points and a 5-minute Apgar score of less than 9 points were considered to be abnormal.

\section{Data Collection}

Participants were enrolled at birth between November 11, 2017 and May 30, 2018. The data collection included basic personal information of the newborns, information related to the umbilical cord (diameter and soft tissue status), and neonatal health status (growth curve, $\mathrm{SpO}_{2}$, Apgar score, whether oxygen was supplied, transfer to the ICU). The measurements of the umbilical cord diameter were made twice and then averaged, and the value was rounded to two decimal places. The newborn's weight, head circumference, and length were re-measured three times and the largest number was used. The body weight and Apgar score at birth were measured in the delivery room.

\section{Statistical Analysis}

The collected data were analyzed using SPSS version 24.0 (IBM Corp., Armonk, NY, USA). The newborns' general characteristics and health status were presented in terms of real numbers, percentages, averages, and standard deviations. The t-test and analysis of variance were conducted to compare differences in umbilical cord diameter according to general characteristics. The $x^{2}$ test and the Fisher exact test were performed to examine the difference in the soft tissue status of the umbilical cord according to general characteristics. The t-test was used to analyze neonatal health status according to the umbilical cord diameter. The $x^{2}$ test was used to analyze neonatal health status according to the soft tissue status of the umbilical cord.

\section{Ethical Considerations}

This study did not involve invasive procedures such as administering drugs to patients or collecting blood, and approval from the Catholic University Medical Center (CMC) Institutional Review Board (IRB) (no. KC17OESI0646) was obtained 
prior to conducting the study. Before providing written informed consent, the mothers of the newborns received an explanation of the purpose of the research, confidentiality, and privacy, and they were informed that their personal information would be used only for research purposes and that they could withdraw from the research at any time. The mothers of the subjects of this study were given the contact information of the IRB of CMC and were allowed to consult with the IRB regarding any questions, concerns, or complaints that are not answered by the researchers or if they had questions about their rights. A small gift was given to the mothers as a token of appreciation.

\section{RESULTS}

\section{General Characteristics of the Participants}

The general characteristics of the newborns, including sex, age of the mother, birth order, delivery type, gestational age, and whether premature rupture of membranes occurred, are shown in Table 1.

The mother's age was between 30 and 34 years for 88 infants (51.2\%), between 35 and 43 years for $34.9 \%$ of neonates, and 29 years or under for $13.9 \%$ of neonates. Eighty-eight newborns (51.2\%) were male, while $84(48.8 \%)$ were female. The majority of the subjects $(n=99 ; 57.6 \%)$ were firstborns. Ninety-six

Table 1. General Characteristics and Health Status of Newborns

$(N=172)$

\begin{tabular}{|c|c|c|c|c|}
\hline Variables & Characteristics & Categories & $\mathrm{n}(\%)$ & $\mathrm{M} \pm \mathrm{SD}$ \\
\hline \multirow{18}{*}{$\begin{array}{l}\text { General } \\
\text { characteristics }\end{array}$} & \multirow[t]{2}{*}{ Sex } & Male & $88(51.2)$ & \\
\hline & & Female & $84(48.8)$ & \\
\hline & \multirow[t]{3}{*}{ Mother's age (year) } & $<30$ & $24(13.9)$ & $33.3 \pm 3.4$ \\
\hline & & $30 \sim 34$ & $88(51.2)$ & \\
\hline & & $35 \sim 43$ & $60(34.9)$ & \\
\hline & \multirow[t]{3}{*}{ Birth order } & 1 st & $99(57.6)$ & \\
\hline & & 2nd & $67(38.9)$ & \\
\hline & & $\geq 3 \mathrm{rd}$ & $6(3.5)$ & \\
\hline & \multirow[t]{2}{*}{ Delivery type } & Spontaneous delivery & $96(55.8)$ & \\
\hline & & Cesarean section & $76(44.2)$ & \\
\hline & \multirow[t]{2}{*}{ PROM } & Yes & $30(17.4)$ & \\
\hline & & None & $142(82.6)$ & \\
\hline & \multirow[t]{6}{*}{ Gestational age (week) } & $<37(35 \sim 36)$ & $11(6.4)$ & $39.1 \pm 2.7$ \\
\hline & & 37 & $28(16.3)$ & \\
\hline & & 38 & $51(29.7)$ & \\
\hline & & 39 & $56(32.5)$ & \\
\hline & & 40 & $21(12.2)$ & \\
\hline & & 41 & $5(2.9)$ & \\
\hline \multirow[t]{12}{*}{ Health status } & \multirow[t]{2}{*}{ Growth curve (percentile) } & Abnormal $(<10 \%$ or $>90 \%)$ & $12(7.0)$ & \\
\hline & & Normal (10 90\%) & $160(93.0)$ & \\
\hline & \multirow[t]{2}{*}{$\mathrm{SpO}_{2}(\%)$} & Abnormal (<95\%) & 37 (21.5) & $96.7 \pm 3.0$ \\
\hline & & Normal ( $\geq 95 \%)$ & $135(78.5)$ & \\
\hline & \multirow[t]{2}{*}{ 1-min Apgar score } & Abnormal $(<8)$ & $14(8.1)$ & $8.4 \pm 0.7$ \\
\hline & & Normal $(\geq 8)$ & $158(91.9)$ & \\
\hline & \multirow[t]{2}{*}{ 5-min Apgar score } & Abnormal $(<9)$ & $7(4.1)$ & $9.5 \pm 0.6$ \\
\hline & & Normal $(\geq 9)$ & $165(95.9)$ & \\
\hline & \multirow[t]{2}{*}{ Oxygen supplied } & Yes & $9(5.2)$ & \\
\hline & & None & $163(94.8)$ & \\
\hline & \multirow[t]{2}{*}{ Transferred to ICU } & Yes & $10(5.8)$ & \\
\hline & & None & $162(94.2)$ & \\
\hline
\end{tabular}

$\mathrm{PROM}=$ Premature rupture of membrane; $\mathrm{SpO}_{2}=$ Saturation of percutaneous oxygen; ICU=Intensive care unit. 
subjects $(55.8 \%)$ were born through natural childbirth and 76 subjects (44.2\%) through caesarean section. The most common gestational age was 39 weeks $(n=56 ; 32.6 \%)$, followed by 38 weeks $(29.7 \%)$, 37 weeks $(16.3 \%)$, and 40 weeks $(12.2 \%)$. The majority of the subjects $(n=142 ; 82.6 \%)$ did not have premature rupture of membranes, while 30 subjects $(17.4 \%)$ had premature rupture of membranes (Table 1 ).

Table 1 presents the distribution of various parameters related to the newborns. Normal growth curves were found for 160 subjects $(93.0 \%)$, while 12 subjects $(7.0 \%)$ had abnormal growth curves. Normal $\mathrm{SpO}_{2}$ was found in 135 newborns (78.5\%), while 37 newborns (21.5\%) had abnormal values for this parameter. Fourteen newborns $(8.1 \%)$ had an abnormal 1-minute Apgar score, while seven (4.1\%) had abnormal 5minute Apgar scores. Nine newborns (5.2\%) were in need of oxygen and 10 newborns (5.8\%) were transferred to the ICU (Table 1).

\section{Differences in Umbilical Cord Diameter after Birth According to General Characteristics}

The average umbilical cord diameter of all subjects was 1.06 $\pm 0.20 \mathrm{~cm}$. No statistically significant difference in the umbilical cord diameter was observed according to birth order, delivery type, or premature rupture of membranes. However, the umbilical cord diameter exhibited a statistically significant difference with respect to $\operatorname{sex}(t=2.21, p=.007)$. The average umbilical cord diameter of male newborns was $1.10 \pm 0.19$ $\mathrm{cm}$, while that of female newborns was $1.02 \pm 0.20 \mathrm{~cm}$ (Table 2).

\section{Differences in the Soft Tissue Status of the Umbilical Cord According to General Characteristics}

A clean umbilical cord was considered to indicate good soft tissue status of the umbilical cord, while stained meconium or the presence of a cyst, hematoma, knot, or thin and unclear umbilical cord was considered to indicate poor soft tissue status of the umbilical cord. The vast majority ( $n=142 ; 82.6 \%)$ of subjects had good soft tissue status of the umbilical cord, while 30 subjects $(17.4 \%)$ had poor soft tissue status of the umbilical cord. The soft tissue status of the umbilical cord did not show statistically significant differences according to gestational age, age of the mother, birth order, delivery type, or premature rupture of membranes (Table 3).

\section{Umbilical Cord Diameter According to Neonatal Health Status}

No statistically significant differences in the cord diameter of newborns were found according to whether newborns

Table 2. Differences in Umbilical Cord Diameter According to General Characteristics

\begin{tabular}{|c|c|c|c|c|c|}
\hline \multirow{2}{*}{ Characteristics } & \multirow{2}{*}{ Categories } & \multirow{2}{*}{$\mathrm{n}$} & Umbilical diameter $(\mathrm{cm})$ & \multirow{2}{*}{ tor $\mathrm{F}$} & \multirow{2}{*}{$p$} \\
\hline & & & $\mathrm{M} \pm \mathrm{SD}$ & & \\
\hline \multirow[t]{2}{*}{ Sex } & Male & 88 & $1.10 \pm 0.19$ & \multirow[t]{2}{*}{2.71} & \multirow[t]{2}{*}{.007} \\
\hline & Female & 84 & $1.02 \pm 0.20$ & & \\
\hline \multirow[t]{3}{*}{ Mother's age (year) } & $<30$ & 24 & $1.10 \pm 0.21$ & \multirow[t]{3}{*}{0.47} & \multirow[t]{3}{*}{.624} \\
\hline & $30 \sim 34$ & 88 & $1.05 \pm 0.20$ & & \\
\hline & $35 \sim 43$ & 60 & $1.06 \pm 0.20$ & & \\
\hline \multirow[t]{3}{*}{ Birth order } & 1st & 99 & $1.05 \pm 0.19$ & \multirow[t]{3}{*}{0.87} & \multirow[t]{3}{*}{.456} \\
\hline & 2nd & 67 & $1.09 \pm 0.23$ & & \\
\hline & $\geq 3 \mathrm{rd}$ & 7 & $0.99 \pm 0.20$ & & \\
\hline \multirow[t]{2}{*}{ Delivery type } & Spontaneous delivery & 96 & $1.04 \pm 0.18$ & \multirow[t]{2}{*}{1.42} & \multirow[t]{2}{*}{.158} \\
\hline & Cesarean section & 76 & $1.09 \pm 0.22$ & & \\
\hline \multirow[t]{2}{*}{ PROM } & Yes & 30 & $1.05 \pm 0.19$ & \multirow[t]{2}{*}{0.26} & \multirow[t]{2}{*}{.796} \\
\hline & None & 142 & $1.06 \pm 0.21$ & & \\
\hline \multirow[t]{6}{*}{ Gestational age (week) } & $<37$ (35 36) & 11 & $1.15 \pm 0.13$ & \multirow[t]{6}{*}{0.30} & \multirow[t]{6}{*}{.938} \\
\hline & 37 & 28 & $1.06 \pm 0.17$ & & \\
\hline & 38 & 51 & $1.08 \pm 0.25$ & & \\
\hline & 39 & 56 & $1.04 \pm 0.20$ & & \\
\hline & 40 & 21 & $1.08 \pm 0.16$ & & \\
\hline & 41 & 5 & $1.06 \pm 0.18$ & & \\
\hline Total & & & $1.06 \pm 0.20$ & & \\
\hline
\end{tabular}

PROM=Premature rupture of membrane. 
showed abnormal or normal findings for the growth curve, 5-minute Apgar score, $\mathrm{SpO}_{2}$, or whether oxygen was supplied immediately after birth. However, a 1-minute Apgar score of less than 8 was significantly associated with a thinner umbilical cord diameter $(t=2.47, p=.015)$. The umbilical cord di- ameter of the newborns who were transferred to the ICU was $0.91 \pm 0.13 \mathrm{~cm}$, which was thinner than that of the newborns who did not have to be transferred to the ICU $(1.07 \pm 0.20 \mathrm{~cm})$, and this difference was statistically significant $(\mathrm{t}=2.45, p=.015)$ (Table 4).

Table 3. Difference in Soft Tissue Status of the Umbilical Cord According to General Characteristics

$(N=172)$

\begin{tabular}{|c|c|c|c|c|c|c|}
\hline \multirow{3}{*}{ Characteristics } & \multirow{3}{*}{ Categories } & \multirow{3}{*}{$\mathrm{n}$} & \multicolumn{2}{|c|}{ Umbilical status } & \multirow{3}{*}{$x^{2}$} & \multirow{3}{*}{$p$} \\
\hline & & & Good $^{*}(n=142)$ & Poor $^{\dagger}(n=30)$ & & \\
\hline & & & $\mathrm{n}(\%)$ & $\mathrm{n}(\%)$ & & \\
\hline \multirow[t]{2}{*}{ Sex } & Male & 88 & $75(52.8)$ & $13(43.3)$ & \multirow[t]{2}{*}{0.89} & \multirow[t]{2}{*}{.345} \\
\hline & Female & 84 & $67(47.2)$ & $17(56.7)$ & & \\
\hline \multirow[t]{3}{*}{ Mother's age (year) } & $<30$ & 24 & $19(13.4)$ & 5 (16.7) & \multirow[t]{3}{*}{2.14} & \multirow[t]{3}{*}{.344} \\
\hline & $30 \sim 34$ & 88 & $70(49.3)$ & $18(60.0)$ & & \\
\hline & $35 \sim 43$ & 60 & $53(37.3)$ & $7(23.3)$ & & \\
\hline \multirow[t]{3}{*}{ Birth order } & 1 st & 99 & $80(56.4)$ & $19(63.4)$ & \multirow[t]{3}{*}{-} & \multirow[t]{3}{*}{$.693^{\dagger}$} \\
\hline & 2nd & 67 & $57(40.1)$ & $10(33.3)$ & & \\
\hline & $\geq 3$ rd & 7 & $5(3.5)$ & $1(3.3)$ & & \\
\hline \multirow[t]{2}{*}{ Delivery type } & Spontaneous delivery & 96 & $79(55.6)$ & $17(56.7)$ & \multirow[t]{2}{*}{0.01} & \multirow[t]{2}{*}{.918} \\
\hline & Cesarean section & 76 & $63(44.4)$ & $13(43.3)$ & & \\
\hline \multirow[t]{2}{*}{ PROM } & Yes & 30 & $117(82.4)$ & $25(83.3)$ & \multirow[t]{2}{*}{0.02} & \multirow[t]{2}{*}{.902} \\
\hline & None & 142 & 25 (17.6) & 5 (16.7) & & \\
\hline \multirow[t]{6}{*}{ Gestational age (week) } & $<37(35 \sim 36)$ & 11 & $11(7.7)$ & $0(0.0)$ & \multirow[t]{6}{*}{-} & \multirow[t]{6}{*}{$.349^{\dagger}$} \\
\hline & 37 & 28 & $22(15.5)$ & $6(20.0)$ & & \\
\hline & 38 & 51 & 45 (31.7) & $6(20.0)$ & & \\
\hline & 39 & 56 & $43(30.3)$ & 13 (43.3) & & \\
\hline & 40 & 21 & 18 (12.7) & $3(10.0)$ & & \\
\hline & 41 & 5 & $3(2.1)$ & $2(6.7)$ & & \\
\hline
\end{tabular}

${ }^{*}$ Clean umbilical cord; ${ }^{\dagger}$ Stained meconium or the presence of a cyst, hematoma, knot, or thin and unclear umbilical cord; ${ }^{\dagger}$ Fisher exact test; PROM=Premature rupture of membrane.

Table 4. Neonatal Health Status According to Umbilical Cord Diameter

$(N=172)$

\begin{tabular}{|c|c|c|c|c|c|}
\hline \multirow{2}{*}{ Health status } & \multirow{2}{*}{ Categories } & \multirow{2}{*}{$\mathrm{n}$} & Umbilical diameter $(\mathrm{cm})$ & \multirow{2}{*}{ tor $F$} & \multirow{2}{*}{$p$} \\
\hline & & & $\mathrm{M} \pm \mathrm{SD}$ & & \\
\hline \multirow[t]{2}{*}{ Growth curve (percentile) } & Abnormal $(<10 \%,>90 \%)$ & 12 & $1.07 \pm 0.21$ & \multirow[t]{2}{*}{1.27} & \multirow[t]{2}{*}{.206} \\
\hline & Normal (10 90\%) & 160 & $0.99 \pm 0.16$ & & \\
\hline \multirow[t]{2}{*}{$\mathrm{SpO}_{2}(\%)$} & Abnormal (<95\%) & 37 & $1.04 \pm 0.23$ & \multirow[t]{2}{*}{0.71} & \multirow[t]{2}{*}{.476} \\
\hline & Normal ( $\geq 95 \%)$ & 135 & $1.07 \pm 0.20$ & & \\
\hline \multirow[t]{2}{*}{ 1-min Apgar score } & Abnormal $(<8)$ & 14 & $0.94 \pm 0.18$ & \multirow[t]{2}{*}{2.47} & \multirow[t]{2}{*}{.015} \\
\hline & Normal $(\geq 8)$ & 158 & $1.07 \pm 0.20$ & & \\
\hline \multirow[t]{2}{*}{ 5-min Apgar score } & Abnormal $(<9)$ & 7 & $0.97 \pm 0.21$ & \multirow[t]{2}{*}{1.29} & \multirow[t]{2}{*}{.198} \\
\hline & Normal $(\geq 9)$ & 165 & $1.07 \pm 0.20$ & & \\
\hline \multirow[t]{2}{*}{ Oxygen supplied } & Yes & 9 & $0.95 \pm 0.10$ & \multirow[t]{2}{*}{1.78} & \multirow[t]{2}{*}{.077} \\
\hline & None & 163 & $1.07 \pm 0.21$ & & \\
\hline \multirow[t]{2}{*}{ Transferred to ICU } & Yes & 10 & $0.91 \pm 0.13$ & \multirow[t]{2}{*}{2.45} & \multirow[t]{2}{*}{.015} \\
\hline & None & 162 & $1.07 \pm 0.20$ & & \\
\hline
\end{tabular}

$\mathrm{SpO}_{2}=$ Saturation of percutaneous oxygen; ICU=Intensive care unit. 


\section{Soft Tissue Status of the Umbilical Cord According to Neonatal Health Status}

There was no statistically significant difference in the soft tissue status of the umbilical cord according to whether newborns showed abnormal or normal findings on the growth curve or $\mathrm{SpO}_{2}$ immediately after birth.

However, an abnormal 1-minute Apgar score was found in $4.2 \%$ of newborns with good soft tissue status of the umbilical cord, and in $26.7 \%$ of newborns with poor soft tissue status of the umbilical cord. There was a statistically significant difference between these two groups $\left(x^{2}=16.68, p<.001\right)$. Oxygen was supplied to $3.5 \%$ of newborns with good soft tissue status of the umbilical cord, and in $13.3 \%$ of newborns with poor soft tissue status of the umbilical cord. This difference was also statistically significant $\left(x^{2}=4.81, p=.028\right)$ (Table 5).

\section{DISCUSSION}

The purpose of this study was to investigate correlations between the diameter and status of the umbilical cord and neonatal health status after birth, thereby encouraging close monitoring of the umbilical cord of newborns after birth by nurses to predict their health status instead of the habitual practice of merely disinfecting and checking the number of veins in the umbilical cord.

The umbilical cord diameter in this study was statistically significantly higher in male newborns, which corresponds to the findings of a previous study that the weight and head circumference of male newborns were greater than those of fe- male newborns [14]. We expected that the umbilical cord diameter would be thicker in newborns with a greater gestational age, but no significant difference was found in this study. Nonetheless, the results of this study correspond with those of previous studies that reported that a thick and healthy umbilical cord in premature newborns who are admitted to the newborn nursery is necessary for their survival $[11,15]$.

Of particular note, the 1-minute Apgar score and transfer to the ICU showed statistically significant relationships with the umbilical cord diameter, in accordance with the findings of other studies that emphasized the importance of observing the umbilical cord status through fetal ultrasound during pregnancy [16-18].

The correlation between the soft tissue status of the umbilical cord and neonatal health status after birth was demonstrated by the statistically significant relationships observed for the 1-minute Apgar score and whether oxygen was supplied. In a study by Räisänen et al. [19], the presence of an umbilical cord knot increased the risk of intensive care for newborns by 1.58 times, newborn death by 8.08 times, and a low 1-minute Apgar score by 1.67 times, corresponding to the findings of this study [20]. Bandyopadhyay et al. [10] and Hiersch et al. [21] reported that newborns born through meconium-stained fluid were more likely to develop newborn jaundice or neonatal sepsis and to require phototherapy, while post mature newborns born through meconium-stained fluid were more likely to develop respiratory distress syndrome than those born through clean amniotic fluid.

The 1-minute Apgar score exhibited a statistically signifi-

Table 5. Neonatal Health Status According to Umbilical Cord Status

$(N=172)$

\begin{tabular}{|c|c|c|c|c|c|c|}
\hline \multirow{3}{*}{ Health status } & \multirow{3}{*}{ Categories } & \multirow{3}{*}{$\mathrm{n}$} & \multicolumn{2}{|c|}{ Umbilical status } & \multirow{3}{*}{$x^{2}$} & \multirow{3}{*}{$p$} \\
\hline & & & Good* $^{*}(n=142)$ & Poor $^{\dagger}(n=30)$ & & \\
\hline & & & $\mathrm{n}(\%)$ & $\mathrm{n}(\%)$ & & \\
\hline \multirow[t]{2}{*}{ Growth curve (percentile) } & Abnormal $(<10 \%$ or $>90 \%)$ & 12 & $10(7.0)$ & $2(6.7)$ & \multirow[t]{2}{*}{0.01} & \multirow[t]{2}{*}{.942} \\
\hline & Normal (10 90\%) & 160 & $132(93.0)$ & $28(93.3)$ & & \\
\hline \multirow[t]{2}{*}{$\mathrm{SpO}_{2}(\%)$} & Abnormal (<95\%) & 37 & $30(21.1)$ & $7(23.3)$ & \multirow[t]{2}{*}{0.07} & \multirow[t]{2}{*}{.789} \\
\hline & Normal ( $\geq 95 \%)$ & 135 & $112(78.9)$ & $23(76.7)$ & & \\
\hline \multirow[t]{2}{*}{ 1-min Apgar score } & Abnormal $(<8)$ & 14 & $6(4.2)$ & $8(26.7)$ & \multirow[t]{2}{*}{16.68} & \multirow[t]{2}{*}{$<.001$} \\
\hline & Normal $(\geq 8)$ & 158 & $136(95.8)$ & $22(73.3)$ & & \\
\hline \multirow[t]{2}{*}{ 5-min Apgar score } & Abnormal $(<9)$ & 7 & $4(2.8)$ & $3(10.0)$ & \multirow[t]{2}{*}{3.27} & \multirow[t]{2}{*}{.070} \\
\hline & Normal $(\geq 9)$ & 165 & $138(97.2)$ & $27(90.0)$ & & \\
\hline \multirow[t]{2}{*}{ Oxygen supplied } & Yes & 9 & $5(3.5)$ & $4(13.3)$ & \multirow[t]{2}{*}{4.81} & \multirow[t]{2}{*}{.028} \\
\hline & None & 163 & $137(96.5)$ & $26(86.7)$ & & \\
\hline \multirow[t]{2}{*}{ Transferred to ICU } & Yes & 10 & $7(4.9)$ & $3(10.0)$ & \multirow[t]{2}{*}{1.16} & \multirow[t]{2}{*}{.281} \\
\hline & None & 162 & $135(95.1)$ & $27(90.0)$ & & \\
\hline
\end{tabular}

${ }^{*}$ Clean umbilical cord; ${ }^{\dagger}$ Stained meconium or the presence of a cyst, hematoma, knot, and thin or unclear umbilical cord; $\mathrm{SpO}{ }_{2}=\mathrm{Saturation}$ of percutaneous oxygen; ICU=Intensive care unit. 
cant difference with respect to the umbilical cord diameter and poor soft tissue status of the umbilical cord; therefore, the soft tissue status of the umbilical cord is closely related to neonatal health status after birth. The importance of umbilical cord care for monitoring newborns after birth has been highlighted in numerous studies $[3,22,23]$. Disinfecting the umbilical cord was considered important in the past, whereas natural drying is deemed more important at present [3]. Monitoring newborns is a delicate task, but it is one that is absolutely vital to a baby's well-being in the first few minutes of life and, in some instances, beyond. Even an assessment of the umbilical cord diameter and soft tissue status of the umbilical cord through close observations with the naked eye, without directly measuring the umbilical cord diameter, can be important. If the umbilical cord diameter is small or the soft tissue status of the umbilical cord is poor, newborns should be assessed to determine whether oxygen needs to be provided or the newborn needs to be transferred to the ICU as part of caring for newborns before the separation of the umbilical cord. In addition to disinfecting and observing the veins of the umbilical cord, it should become part of routine practice to observe the diameter and status of the umbilical cord and to record the relevant information.

\section{CONCLUSION}

This study is significant in that it demonstrated that the umbilical cord diameter and status after birth predicted the health status of neonates. Poor soft tissue status of the umbilical cord can be a predictive sign of whether newborns admitted to the newborn nursery need to be transferred to the ICU, and the umbilical cord therefore requires close monitoring [24]. Newborns with poor umbilical cord status showed significantly lower 1-minute Apgar scores and a higher likelihood of requiring oxygen administration immediately after birth. Newborns with thin umbilical cords showed significantly impaired access to nutrients and oxygenation, leading to a low Apgar score at 1 minute immediately after birth and a higher likelihood of transfer to the intensive care unit [25]. Therefore, neonatal nurses should not only disinfect and observe the veins of the umbilical cord, but should also observe the diameter and status of the umbilical cord and record the relevant information. Newborns at 35 and 36 weeks had a thicker umbilical cord diameter and were more likely to have good soft tissue status of the umbilical cord, but this difference was not statistically significant.

The results of this study cannot be generalized to all newborns since the subjects were newborns at a single institution, and further studies on umbilical cord diameter and status must therefore be conducted domestically. Nonetheless, this study may contribute to improving the quality of newborn care, as it is the first research conducted in Korea to examine the effects of umbilical cord diameter and status on neonatal health status.

\section{Conflict of interest}

No existing or potential conflict of interest relevant to this article was reported.

\section{REFERENCES}

1. Binbir B, Yeniel AO, Ergenoglu AM, Kazandi M, Akercan F, Sagol $\mathrm{S}$. The role of umbilical cord thickness and $\mathrm{HbA1}$ l levels for the prediction of fetal macrosomia in patients with gestational diabetes mellitus. Archives of Gynecology Obstetrics. 2012;285(3):635-639. https://doi.org/10.1007/s00404-011-1961-3

2. Charles E, Mabel U, Cletus E, George U, Kennedy A, Ozalla I. Relationship between sonographic umbilical cord size and gestational age among pregnant women in Enugu, Nigeria. African Health Sciences. 2014;14(2):334-338.

3. López-Medina MD, López-Araque AB, Linares-Abad M, LópezMedina IM. Umbilical cord separation time, predictors and healing complications in newborns with dry care. PLoS One. 2020;15 (1):e0227209. https://doi.org/10.1371/journal.pone.0227209

4. Damasceno EB, de Lima PP. Wharton's jelly absence: A possible cause of stillbirth. Autopsy and Case Reports. 2013;3(4):43-47. https://doi.org/10.4322/acr.2013.038

5. Nosan G, Paro-Panjan D. Umbilical cord care: National survey, literature review and recommendations. The Journal of MaternalFetal \& Neonatal Medicine. 2017;30(14):1655-1658. https://doi.org/10.1080/14767058.2016.1220530

6. Ikechebelu J, Eleje G, Ofojebe C. True umbilical cord knot leading to fetal demise. Annals of Medical and Health Sciences Research. 2014;4(Suppl 2):S155-158. https://doi.org/10.4103/2141-9248.138044

7. Proctor L, Fitzgerald B, Whittle W, Mokhtari N, Lee E, Machin G, et al. Umbilical cord diameter percentile curves and their correlation to birth weight and placental pathology. Placenta. 2013;34(1):62-66.

8. Duman NB, Topuz S, Bostanci MO, Gorkem U, Kocak DY, Togrul $\mathrm{C}$, et al. The effects of umbilical cord entanglement upon labor management and fetal health: Retrospective case control study. The Journal of Maternal-Fetal \& Neonatal Medicine. 2018;31(5): 656-660. https://doi.org/10.1080/14767058.2017.1293033

9. Boujenah J, Oliveira J, De La Hosseraye C, Benbara A, Tigaizin A, Bricou A, et al. Should fetal scalp blood sampling be performed in the case of meconium-stained amniotic fluid? The Journal of Maternal-Fetal \& Neonatal Medicine. 2016;29(23):3875-3878. https://doi.org/10.3109/14767058.2016.1149567

10. Bandyopadhyay T, Bhatia BD, Khanna HD. A study of oxidative 
stress in neonates delivered through meconium-stained amniotic fluid. European Journal of Pediatrics. 2017;176(3):317-325.

https://doi.org/10.1007/s00431-016-2845-0

11. Karumbi J, Mulaku M, Aluvaala J, English M, Opiyo N. Topical umbilical cord care for prevention of infection and neonatal mortality. The Pediatric Infectious Disease Journal. 2013;32(1):78-83. https://doi.org/10.1097/INF.0b013e3182783dc3

12. Li F, Wu T, Lei X, Zhang H, Mao M, Zhang J. The apgar score and infant mortality. PLoS One. 2013;8(7):e69072.

https://doi.org/10.1371/journal.pone.0069072

13. WHO Multicentre Growth Reference Study Group. WHO Child Growth Standards based on length/height, weight and age. Acta Paediatrica. 2006;450:76-85. https://doi.org/10.1111/j.1651-2227.2006.tb02378.x

14. Lehre AC, Laake P, Sexton JA. Differences in birth weight by sex using adjusted quantile distance functions. Statistics in Medicine. 2013;32(17):2962-2970. https://doi.org/10.1002/sim.5744

15. Ertürk N. Umbilical cord diameter at the junction of the body wall in the newborn. Is it a biomarker for congenital umbilical hernia? Fetal and Pediatric Pathology. 2018;37(4):223-230. https://doi.org/10.1080/15513815.2018.1477886

16. Tahmasebi M, Alighanbari R. Evaluation of umbilical cord thickness, cross-sectional area, and coiling index as predictors of pregnancy outcome. Indian Journal of Radiology and Imaging. 2011; 21(3):195-198. https://doi.org/10.4103/0971-3026.85367

17. Cromi A, Ghezzi F, Di Naro E, Siesto G, Bergamini V, Raio L. Large cross-sectional area of the umbilical cord as a predictor of fetal macrosomia. Ultrasound in Obstetrics and Gynecology. 2007;30(6): 861-866. https://doi.org/10.1002/uog.5183

18. Begum K, Ahmed MU, Rahman MM, Hossain MM, Begum M, Sarkar SK, et al. Correlation between umbilical cord diameter and cross sectional area with gestational age and foetal anthropometric parameters. Mymensingh Medical Journal. 2016;25(2):190-197.

19. Räisänen S, Georgiadis L, Harju M, Keski-Nisula L, Heinonen S. True umbilical cord knot and obstetric outcome. International Journal of Gynecology and Obstetrics. 2013;122(1):18-21. https://doi.org/10.1016/j.ijgo.2013.02.012

20. Di Naro E1 GF, Raio L, Franchi M, D'Addario V. Umbilical cord morphology and pregnancy outcome. European Journal of Obstetrics, Gynecology, and Reproductive Biology. 2001;96(2):150-157. https://doi.org/10.1016/s0301-2115(00)00470-x

21. Hiersch L, Krispin E, Linder N, Aviram A, Gabbay-Benziv R, Yogev $\mathrm{Y}$, et al. Meconium-stained amniotic fluid and neonatal morbidity in low-risk pregnancies at term: The effect of gestational age. American Journal of Perinatology. 2017;34(2):183-190. https://doi.org/10.1055/s-0036-1585056

22. Nankabirwa V, Tylleskär T, Tumuhamye J, Tumwine JK, Ndeezi G, Martines JC, et al. Efficacy of umbilical cord cleansing with a single application of $4 \%$ chlorhexidine for the prevention of newborn infections in Uganda: Study protocol for a randomized controlled trial. Trials. 2017;18(1):322.

https://doi.org/10.1186/s13063-017-2050-0

23. Goldenberg RL, McClure EM, Saleem S. A review of studies with chlorhexidine applied directly to the umbilical cord. Am J Perinatol. 2013;30(8):699-702. https://doi.org/10.1055/s-0032-1329695

24. Lei T, Xie HN, Feng JL. Prenatal diagnosis of four-vessel umbilical cord with supernumerary vein varix: A case report and literature review. The Journal of Obstetrics and Gynaecology Research. 2017;43(7):1200-1204. https://doi.org/10.1111/jog.13324

25. Sharma D, Shastri S, Sharma P. Intrauterine growth restriction: Antenatal and postnatal aspects. Clinical Medicine Insights: Pediatrics. 2016;10:67-83. https://doi.org/10.4137/CMPed.S40070 